$\underline{\text { Supporting Information }}$

\title{
Bicomponent Co-assembled Hydrogel as a Template for Selective Enzymatic Generation of DOPA
}

Sagar Biswas, Tapas Ghosh, Deepak K. K. Kori and Apurba K. Das*

Department of Chemistry, Indian Institute of Technology Indore, Indore 453552, India

E-mail: apurba.das@iiti.ac.in 
Table of Contents

\begin{tabular}{|c|l|c|}
\hline Sl. No & \multicolumn{1}{|c|}{ Contents } & Page No. \\
\hline $\mathbf{1}$ & Experimental methods & S3-S4 \\
\hline $\mathbf{2}$ & Optical images of other bi-component systems. (Figure S1) & S5 \\
\hline $\mathbf{3}$ & Rheology and UV-Vis spectra. (Figure S2) & S5 \\
\hline $\mathbf{4}$ & Mass spectrum of synthesized L-DOPA in hydrogel medium. (Figure S3) & S6 \\
\hline $\mathbf{5}$ & $\begin{array}{l}\text { Conversion of L-DOPA within the DAN-BTC hydrogel (a) at different } \\
\text { concentration of tyrosinase (at constant L-tyrosine concentration of 20 } \\
\text { mM), (b) at different concentration of L-tyrosine (at constant tyrosinase } \\
\text { concentration of 1 mg/mL). (Figure S4) }\end{array}$ & S6 \\
\hline $\mathbf{6}$ & $\begin{array}{l}\text { Optical images of L-tyrosine in TNE buffer (pH-7.4) (without hydrogel) at } \\
\text { different time interval of enzymatic reaction. (Figure S5) }\end{array}$ & S7 \\
\hline $\mathbf{7}$ & $\begin{array}{l}\text { HPLC chromatograms of enzymatic reaction of L-tyrosine (20 mM) in } \\
\text { presence of tyrosinase enzyme (1 mg/mL) at TNE buffer (pH-7.4; 25 } \\
\text { mM) showing the formation of dopaquinone at higher retention time from } \\
\text { L-tyrosine. (Figure S6) }\end{array}$ & $\begin{array}{l}\text { Mass spectrum of dopaquinone formed from L-tyrosine in presence of } \\
\text { tyrosinase. (Figure S7) }\end{array}$ \\
\hline
\end{tabular}




\section{Experimental methods}

\section{Rheological Study}

Rheological experiment was assessed using an Anton Paar Physica Rheometer (MCR 301, Austria) with parallel plate geometry (25 mm in diameter, $1 \mathrm{~mm}$ gap) and temperature was controlled at $25{ }^{\circ} \mathrm{C}$. The dynamic modulus of the hydrogel was measured as a function of frequency in the range of $0.05-100 \mathrm{rad} \mathrm{s}^{-1}$ with a constant strain value $0.1 \%$. The dynamic behavior of hydrogel during enzymatic reaction was performed with constant strain of $0.1 \%$ and constant angular frequency of $10 \mathrm{~Hz} .200 \mu \mathrm{L}$ of hydrogel was prepared in glass vial and transferred it over the plate using microspatula to proceed for rheological measurements.

\section{Fluorescence Study}

The fluorescence spectra of DAN-BTC hydrogel was recorded on a Horiba Scientific FluoroMax-4 spectrophotometer at room temperature. The slit width for the emission spectra was set at $5 \mathrm{~nm}$ and the data pitch was $1 \mathrm{~nm}$. Emission spectra of the DAN-BTC hydrogel was recorded at $\lambda_{\text {ex }}$ of $320 \mathrm{~nm}$ and the data range was $330-600 \mathrm{~nm}$. The fluorescence spectra of individual DAN and BTC were also recorded at same excitation wavelength for comparison.

\section{Morphological study}

Field emission scanning electron microscope (FE-SEM, Supra 55 Zeiss) was used for SEM study. Gels were dried on cover slip and coated with gold for SEM analysis with an operating voltage of $5 \mathrm{kV}$. Field Emission Gun-Transmission Electron Microscope (model: Tecnai G2, F30), operated on a voltage of $300 \mathrm{kV}$ was used for TEM analysis. $100 \mu \mathrm{L}$ of gel was dissolved in $200 \mu \mathrm{L}$ of water and the dilute solution of the hydrogels was dried on carbon-coated copper grids (300 mesh) by slow evaporation in air and then allowed to dry separately in a vacuum at room temperature. Phosphotungstic acid $(0.2 \%$, w/v) was used as negative stain for TEM analysis.

\section{FT-IR Spectroscopy}

All reported FT-IR spectra were recorded with a Bruker (Tensor 27) FT-IR spectrophotometer. The solid-state measurements were performed using the $\mathrm{KBr}$ pellet technique with a scan range between 400 and $4000 \mathrm{~cm}^{-1}$ over 64 scans at a resolution of $4 \mathrm{~cm}^{-1}$ and an interval of $1 \mathrm{~cm}^{-1}$. The hydrogel was dried in vacuum prior to the experiment. 


\section{UV-vis Spectroscopy}

UV-Vis absorption spectra were recorded using a Varian Cary100 Bio UV-Vis spectrophotometer at a concentration of $5 \mu \mathrm{M}$ in $2 \mathrm{~mL}$ of TNE buffer solution $(10 \mathrm{mM})$.

\section{Wide Angle X-ray Diffraction}

The XRD measurements were carried out using a Bruker D8 Advance X-ray diffractometer. The $\mathrm{X}$-rays were produced using a sealed tube, and the wavelength of the X-rays was $0.154 \mathrm{~nm}(\mathrm{Cu}$ $\mathrm{Ka}$ ). The X-rays were detected using a fast counting detector based on silicon strip technology (Bruker LynxEye detector).

\section{Enzymatic Reaction in only TNE buffer}

The enzyme tyrosinase $(1 \mathrm{mg} / \mathrm{mL})$ was dissolved in $1 \mathrm{~mL} 25 \mathrm{mM}$ TNE buffer $(\mathrm{pH}=7.4)$. In a 3 $\mathrm{mL}$ glass vial, $700 \mu \mathrm{L}$ of $25 \mathrm{mM}$ TNE buffer $(\mathrm{pH}=7.4)$ was placed. Then individually $100 \mu \mathrm{L}$ of L-tyrosine $(20 \mathrm{mM})$ with $200 \mu \mathrm{L}$ of tyrosinase solution were added to the gel to make the final volume $1 \mathrm{~mL}$. The resultant solution was kept at room temperature and the product conversion was monitored by HPLC and visually.

\section{HPLC Analysis}

A Dionex HPLC-Ultimate 3000 (High Performance Liquid Chromatography) pump was used to analyze products. $20 \mu \mathrm{L}$ of sample was injected onto a Dionex Acclaim ${ }^{\circledR} 120 \mathrm{C} 18$ column of $250 \mathrm{~mm}$ length with an internal diameter of $4.6 \mathrm{~mm}$ and $5 \mu \mathrm{m}$ fused silica particles at a flow rate of $1 \mathrm{~mL} \mathrm{~min} \mathrm{~m}^{-1}$ (linear gradient of $20 \% \mathrm{v} / \mathrm{v}$ acetonitrile in water for 4 minutes, gradually rising to $80 \%(\mathrm{v} / \mathrm{v})$ acetonitrile in water at $35 \mathrm{~min}$ ). This concentration was kept constant until $40 \mathrm{~min}$ when the gradient was decreased to $20 \%(\mathrm{v} / \mathrm{v})$ acetonitrile in water at $42 \mathrm{~min}$. The sample preparation was involved with mixing of $100 \mu \mathrm{L}$ hydrogel in $900 \mu \mathrm{L}$ acetonitrile-water (50: 50 mixtures) solution containing $0.1 \%$ trifluroacetic acid. The samples were then filtered through a $0.45 \mu \mathrm{m}$ syringe filter (Whatman, 150 units, $13 \mathrm{~mm}$ diameter, $2.7 \mathrm{~mm}$ pore size) prior to injection. The products were identified by using Ultimate 3000 RS Variable Wavelength Detector at $280 \mathrm{~nm}$. 


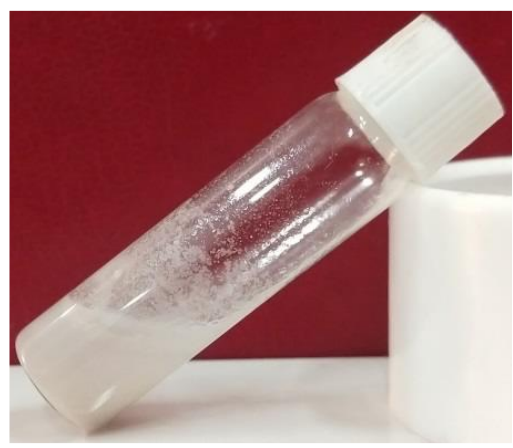

DAN-BDC

$(1: 1)$

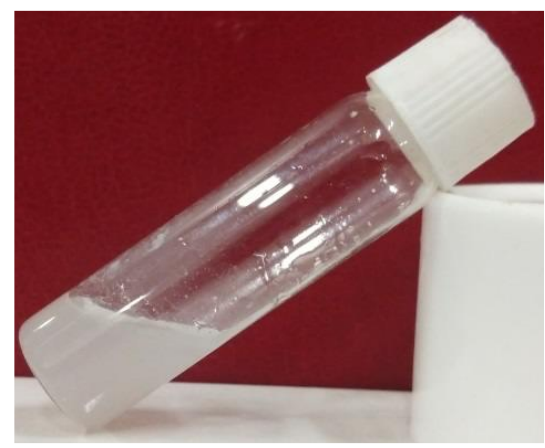

DAN-SA

$(1: 1)$

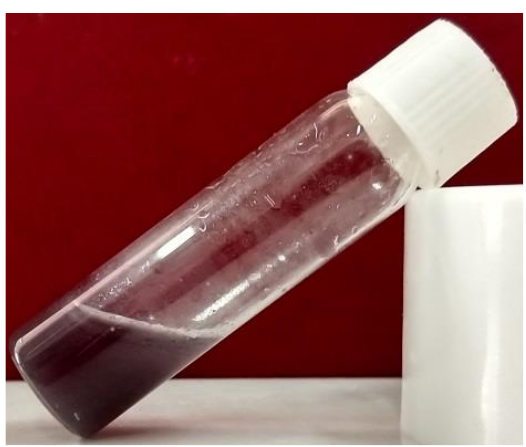

DAN-BCA

$(1: 1)$

Figure S1. Optical images of other bicomponent systems. DAN: 1,5-diaminonaphthalene, BDC: 1,4-benzenedicarboxylic acid, SA: succinic acid and BCA: benzoic acid. All are mixture of 45 $\mathrm{mM}$ of DAN and $30 \mathrm{mM}$ of each acid.
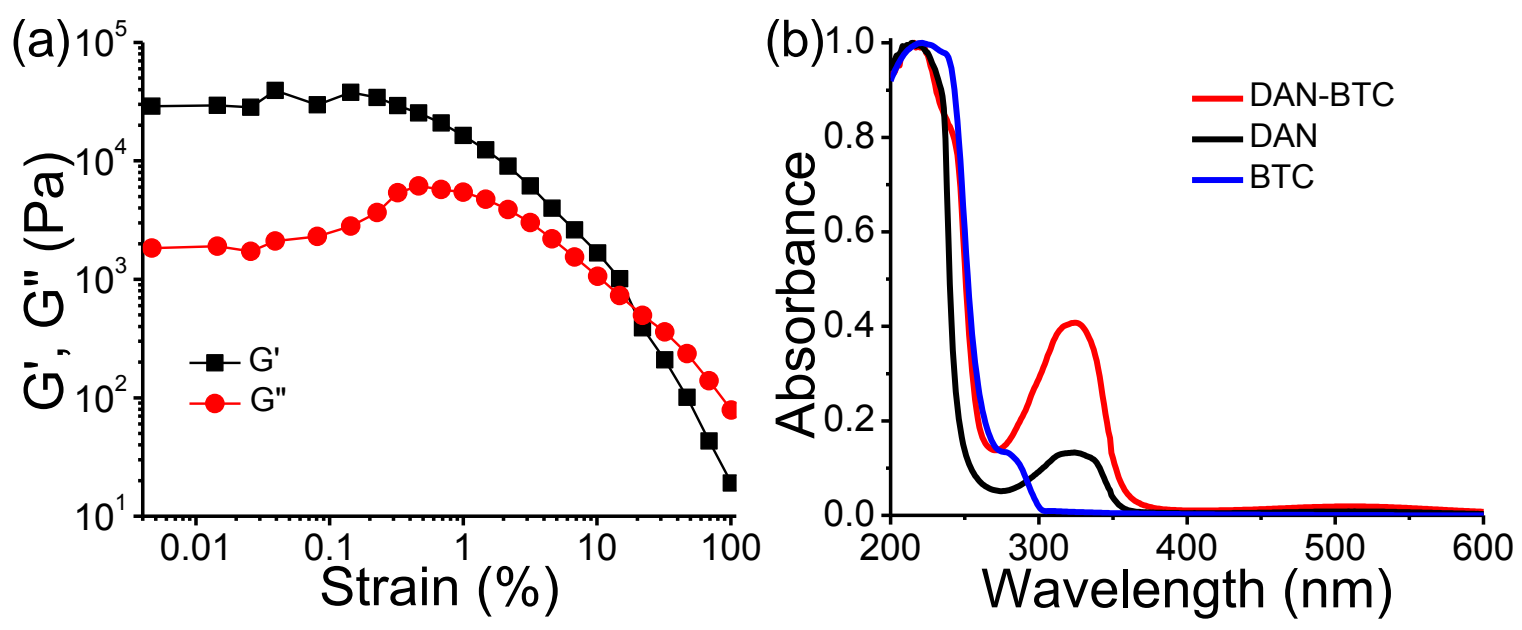

Figure S2. (a) Amplitude sweep rheological data showing gel deformation after an applied strain 10\%. (b) The comparison of UV-vis spectra of DAN-BTC. 


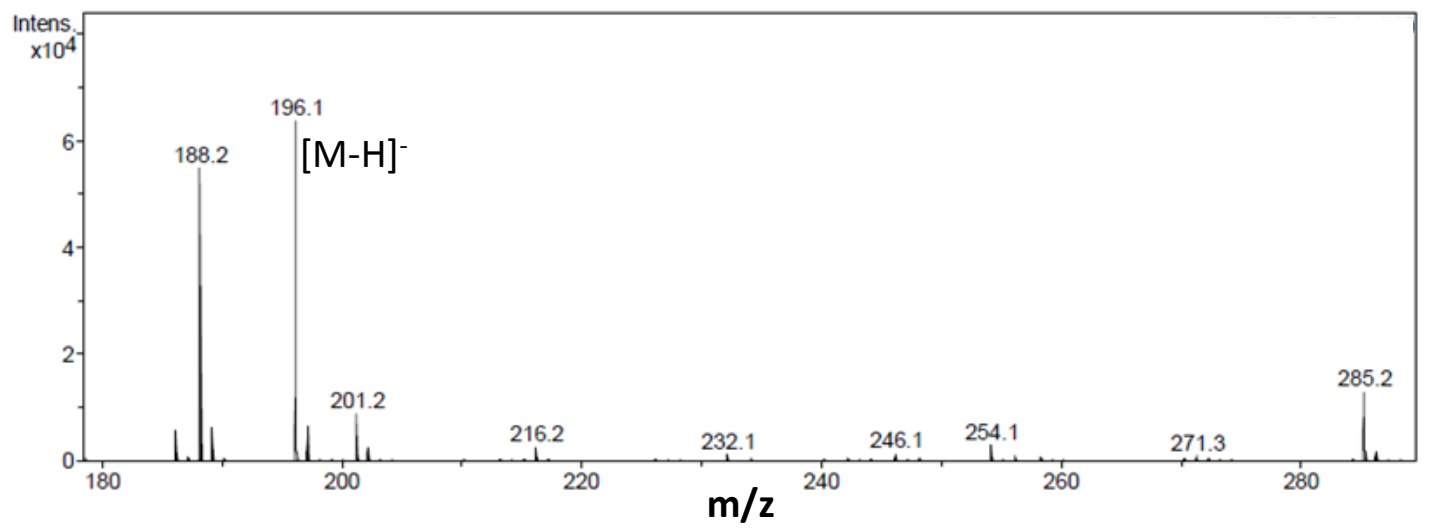

Figure S3. Mass spectrum of synthesized L-DOPA in hydrogel medium.
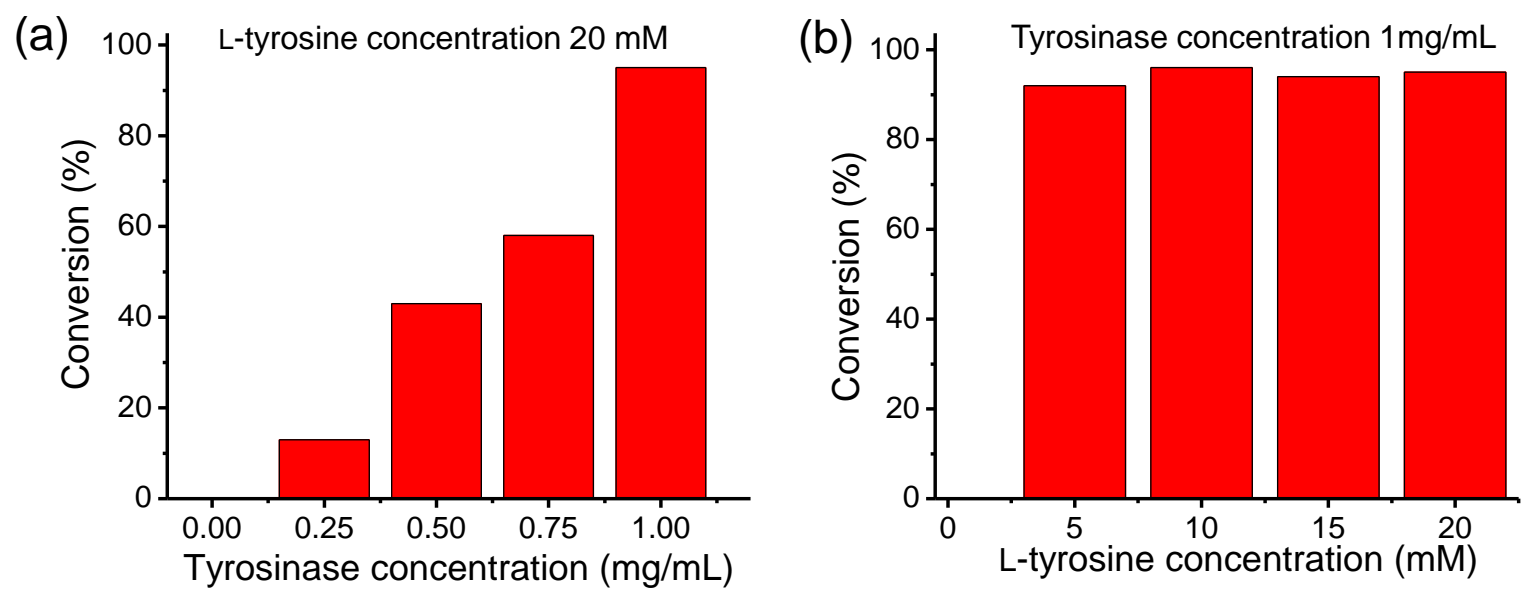

Figure S4. Conversion of L-DOPA within the DAN-BTC hydrogel (a) at different concentration of tyrosinase (at constant L-tyrosine concentration of $20 \mathrm{mM}$ ), (b) at different concentration of Ltyrosine (at constant tyrosinase concentration of $1 \mathrm{mg} / \mathrm{mL}$ ). 


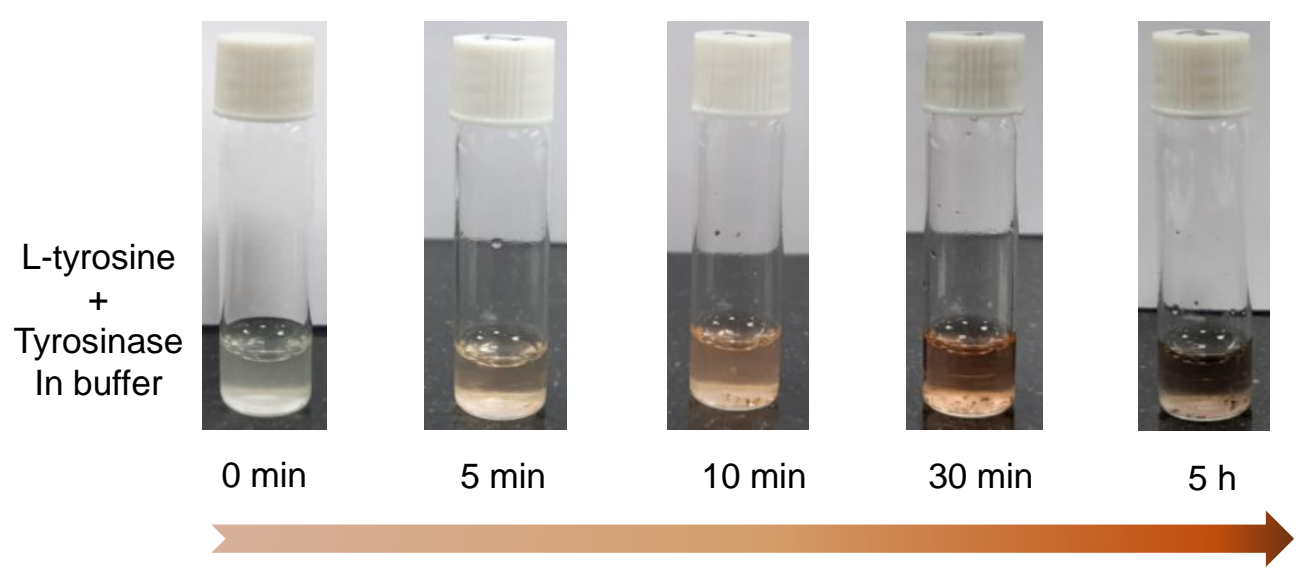

Gradual changes in color clearly indicates the formation of dopaquinone and higher oligomers

Figure S5. Optical images of L-tyrosine in TNE buffer ( $\mathrm{pH} 7.4)$ (without hydrogel) at different time interval of enzymatic reaction.

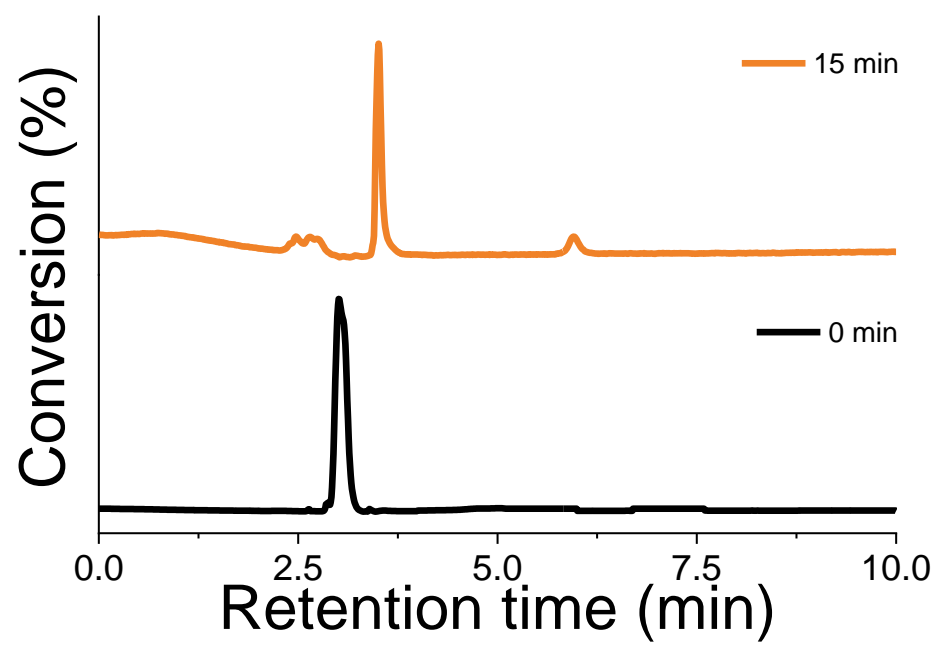

Figure S6. HPLC chromatograms of enzymatic reaction of L-tyrosine $(20 \mathrm{mM})$ in presence of tyrosinase enzyme $(1 \mathrm{mg} / \mathrm{mL})$ at TNE buffer $(\mathrm{pH}-7.4 ; 25 \mathrm{mM})$ showing the formation of dopaquinone at higher retention time from L-tyrosine. 


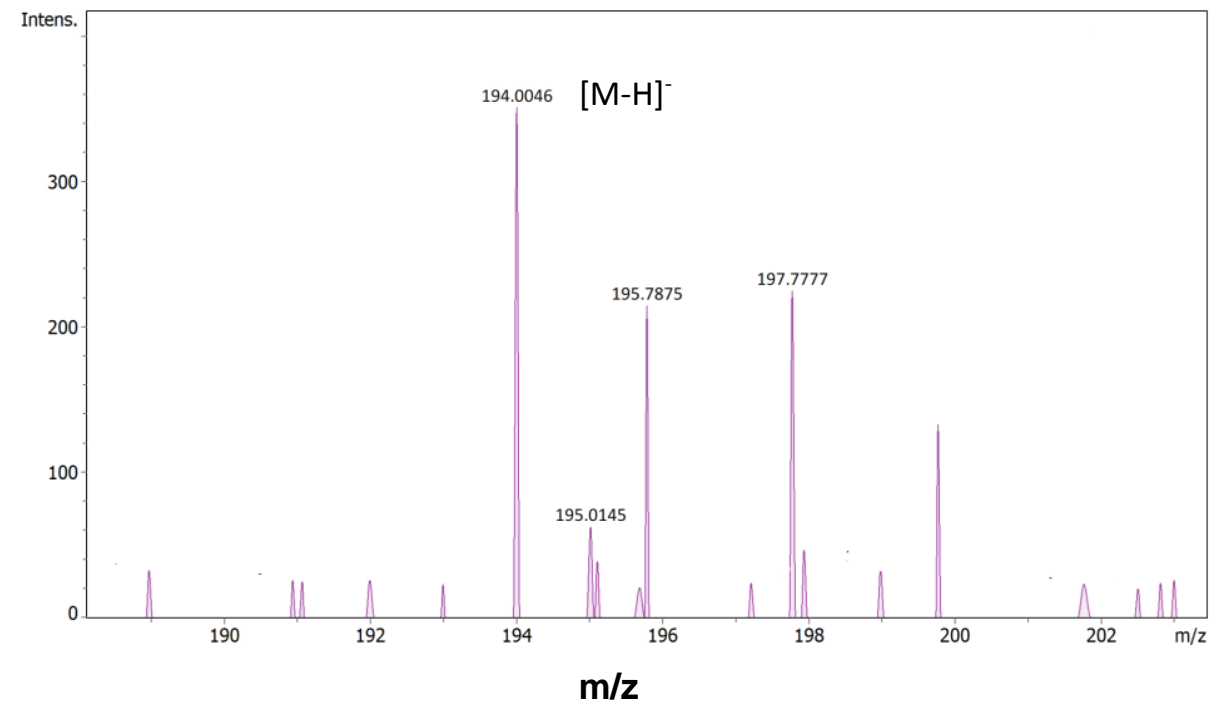

Figure S7. Mass spectrum of dopaquinone formed from L-tyrosine in presence of tyrosinase. ESI-MS: m/z: [M-H] ${ }^{-}$calcd for $\mathrm{C}_{9} \mathrm{H}_{9} \mathrm{NO}_{4}$ 194.0448; found 194.0046 